\title{
Rib cage mechanics after median sternotomy
}

\author{
T J Locke, T L Griffiths, H Mould, G J Gibson
}

\begin{abstract}
A substantial reduction in lung volumes occurs after sternotomy, but the mechanism or mechanisms are unclear. Measurements were made of lung volumes and of chest wall motion with four pairs of magnetometers (two pairs for anteroposterior rib cage, one for lateral rib cage, and one for anteroposterior abdominal dimensions) in 16 men before and one week and three months after coronary artery grafting. Reductions in all lung volumes occurred after sternotomy and were greater in the supine than in the sitting position. Supine vital capacity was reduced one week after surgery, with almost complete recovery at three months. One week after sternotomy there was a significant reduction in tidal volume from a mean (95\% confidence limits) value of $0.88(0.76-1.00)$ litre to $0.61(0.52-0.70) 1$, and in supine rib cage displacement from $3.87(1.96-5.78) \mathrm{mm}$ to $0.44(-0.61-$ $1.49) \mathrm{mm}$ in the lateral plane. Respiratory frequency increased from 16 (13-19) to $21(19-24) / \mathrm{min}$. Coordination of the rib cage was assessed by measuring the difference in timing of onset of chest wall motion and airflow in four planes. At one week nine of 14 patients showed uncoordination between airflow and rib cage motion in one or more dimensions, and this was still present in three patients at three months. No loss of the temporal relation between airflow and abdominal wall motion was detected. The results suggest that reduced and uncoordinated rib cage expansion contributes to the restrictive ventilatory defect that follows median sternotomy.
\end{abstract}

Department of Cardiothoracic Surgery

T J Locke

Department of Respiratory Medicine, Freeman Hospital, Newcastle upon Tyne T L Griffiths

T L Mould

G J Gibson

Address for reprint requests: Mr T J Locke, Department of Cardiothoracic Surgery, Northern General Hospital, Sheffield S5 7AU.

Accepted 21 February 1990

A restrictive ventilatory defect follows median sternotomy. ${ }^{1-7}$ Vital capacity (VC), $\mathrm{FEV}_{1}$, and function residual capacity (FRC) may fall to as little as $40 \%$ of preoperative values one to three days after coronary artery bypass grafting, ${ }^{6}$ and the changes are generally more pronounced after use of the internal mammary artery than after saphenous vein grafting. ${ }^{6}$ By the end of the first postoperative week lung volumes are increasing, ${ }^{7}$ and at three months recovery is almost complete. ${ }^{7}$ The mechanism or mechanisms of volume reduction and recovery are not clear. In the early postoperative days pain and atelectasis are likely to unlikely to be a major cause of a persisting ventilatory defect. At this stage other mechanisms, such as diaphragmatic palsy, ${ }^{4}$ the effects of pleurotomy, ${ }^{35}$ or abnormal chest wall mechanics, may be important.

The present study was performed to determine the contribution of altered chest wall mechanics to the restrictive ventilatory defect that follows median sternotomy.

\section{Methods}

PATIENTS

We studied lung volumes and rib cage motion in 16 men (age range 47-64, mean 54 years) with chronic stable angina and good left ventricular function before and after coronary artery surgery. Eleven were ex-smokers and two had mild airways obstruction $\left(\mathrm{FEV}_{1} / \mathrm{VC}\right.$ $60-70 \%$, VC normal). Patients with $\mathrm{FEV}_{1} / \mathrm{VC}$ below $60 \%$, chest radiographic abnormalities, or valvular heart disease were excluded from the study.

\section{SURGERY}

All patients underwent isolated coronary artery grafting with no additional procedures; 10 had internal mammary artery and saphenous vein grafts and six had only saphenous vein grafts. Myocardial protection comprised systemic hypothermia, single dose cold cardioplegia, and topical hypothermia; ischaemic times ranged from 33 to 98 minutes. The sternum was closed with five to nine steel wires. No pleural drains were inserted; if it was entered during harvest of the left internal mammary artery the left pleural space was allowed to drain into the mediastinum via a wide pleurotomy.

\section{MEASUREMENTS}

$\mathrm{FEV}_{1}$ and slow expired vital capacity (VC) were measured in both the upright and supine contribute. At one week, however, pain is positions and static lung volumes (total lung capacity (TLC), functional residual capacity (FRC), and residual volume (RV)) were measured with the subject seated in a whole body plethysmograph. ${ }^{8}$ In addition, displacement of the chest wall was measured during resting tidal breathing with four pairs of linearised magnetometers, ${ }^{9}$ attached to the skin by double sided tape in the positions shown in figure 1. Signals were recorded on a multichannel pen recorder (Lectromed M19). The linear displacement of each pair of magnetometers was calibrated by a standard electrical signal. The patient breathed with a mouthpiece and nose clip through a Fleisch 
Figure 1 Position of one of each pair of magnetometers. Each anterior magnetometer has a corresponding device positioned over the magnet has its pair on the left mid axillary line. thoracic spine. The lateral

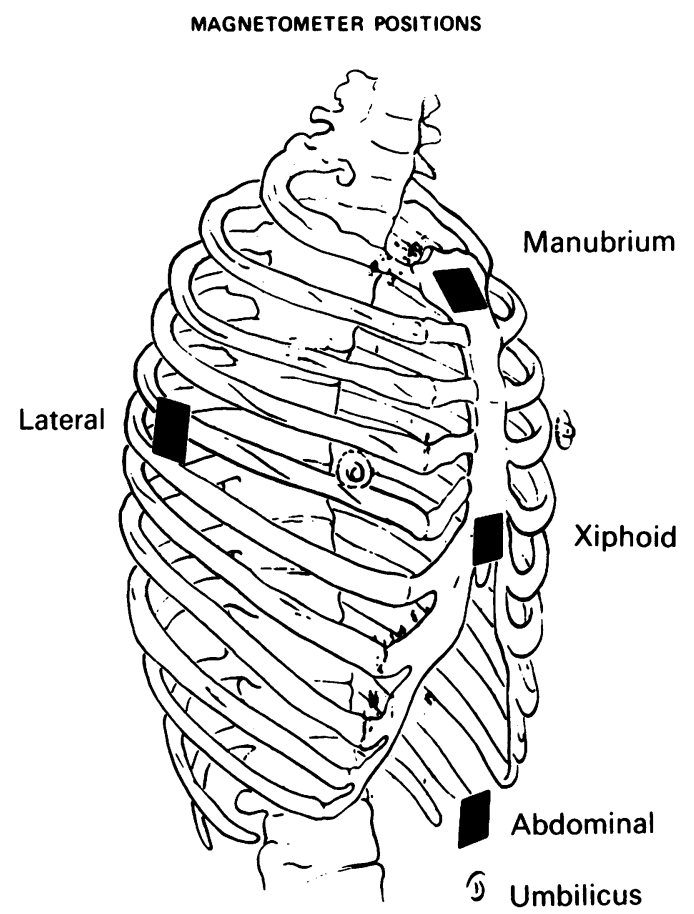

pneumotachograph to allow accurate identification of the phases of respiration, and the output from the pneumotachograph was integrated electrically to give tidal volume.

In normal subjects during tidal breathing the chest wall moves symmetrically with linear and volume expansion of its rib cage and abdominal compartments closely related in time. ${ }^{10}$ When chest wall expansion is distorted differences in phase arise between motion in different dimensions. The distortions are conveniently quantified by assuming that volume displacement and linear motion approximate to a sine wave and by measuring the "phase angle" between the two signals (fig 2). Although chest wall expansion does not strictly follow a sine wave pattern, a similar approach has been applied successfully in quantifying rib cage distortion in severe asthma. ${ }^{11}$ In the present study phase angles between linear and volume displacement were measured for each dimension in each of a sequence of five

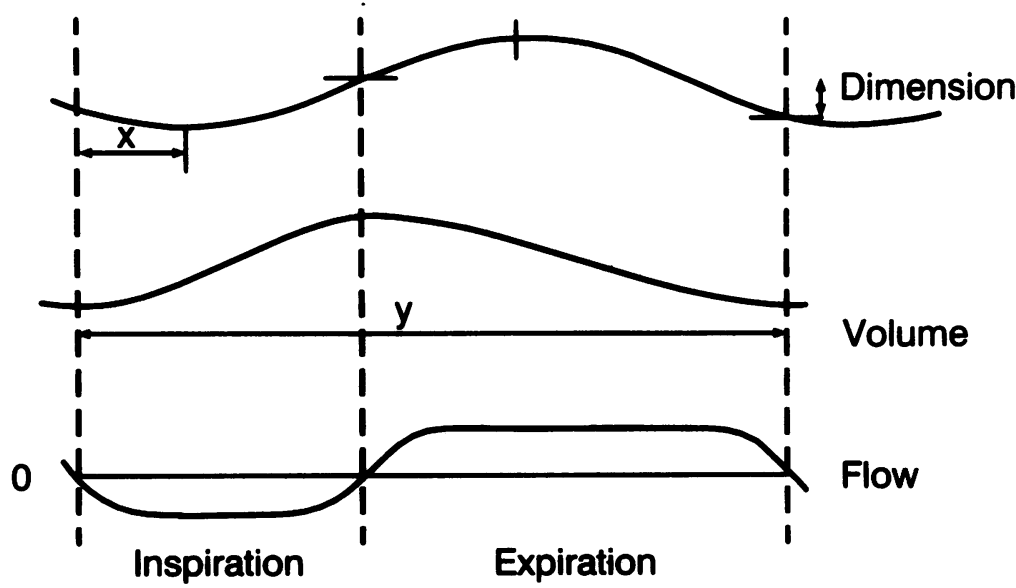

Figure 2 Record of change in a given dimension, tidal volume, and flow during a single breathing cycle. Chest wall displacement (upper trace) is shown as a sine wave and is delayed by comparison with the reference point of zero flow (lower trace) in this example by time $x$. The phase angle between change in dimension and airflow was calculated as a proportion of the total cycle length-that is, $x / y \times 360^{\circ}$. The difference between the horizontal line on the upper record indicates the net linear displacement between end expiration and end inspiration. breaths on each occasion the patient was studied. In addition, the amplitudes of volume and linear displacements from end expiration to end inspiration were calculated during a further 60 breaths. The net linear displacement defined in this way is inevitably affected by the phase angle; in the example shown in figure 2 delay in linear motion (positive phase angle) implies reduced expansion in this dimension between end expiration and end inspiration. In the most extreme case dimensional change would be of opposite sign to volume change throughout the cycle and the corresponding "phase angle" would be $180^{\circ}$.

Baseline ranges for phase angles for each dimension were established from the preoperative study and postoperative values outside this range of mean and two standard deviations were regarded as abnormal.

In eight patients respiratory muscle function was assessed by recording maximum static inspiratory (PImax) and expiratory (PEmax) pressures at the mouth. Expiratory efforts were initiated at TLC and inspiratory efforts at FRC; the values recorded were sustained for at least one second and represented the best of three efforts.

Patients were studied before and one week and three months after operation. Two patients declined magnetometer measurements at one week. In all cases a chest radiograph was available within two days of the first postoperative study day; radiographs were not taken at the time of the three month study.

\section{STATISTICS}

In the text and figures data are presented as means with $95 \%$ confidence limits in parentheses. Results before and after surgery were compared by means of the paired $t$ test or the Spearman correlation coefficient $\left(r_{s}\right)$ as appropriate. The number of patients with abnormal phase angles after operation was compared with the number before operation with Fisher's exact test.

\section{Results}

Postoperative respiratory complications evident one week after sternotomy were minor; plate atelectasis was visible radiographically in four patients, and small pleural effusions were present in six; three patients were being treated for acute bronchitis. No patient had radiographic features suggesting phrenic nerve injury. One patient had a left lower brachial plexus injury. There were no instances of sternal dehiscence.

The changes in lung volumes one week and three months after sternotomy are shown in table 1 . As expected, a restrictive ventilatory defect occurred and this had largely recovered at three months. The fall in $\mathrm{FEV}_{1}$ in six patients who had internal mammary grafts (from $3 \cdot 13$ (95\% CL 2.69-3.57) to $1.60(1.24-2.06)$ 1) was similar to that in patients who had only saphenous vein grafts $(3.09(2.55-3.63)$ to 1.65 (1.26$2.04) 1)$. Reductions in lung volumes one week 
Table 1 Lung volumes in the erect posture before and after sternotomy (mean (95\% confidence limits))

\begin{tabular}{|c|c|c|c|c|c|c|}
\hline \multirow[b]{2}{*}{$\begin{array}{l}\mathrm{FEV}_{1}\left(1 \mathrm{~min}^{-1}\right) \\
\operatorname{VC}(1) \\
\operatorname{TLC}(1) \\
\text { FRC (1). } \\
\operatorname{RV}(1)\end{array}$} & \multicolumn{2}{|c|}{ Control } & \multicolumn{2}{|c|}{ One week } & \multicolumn{2}{|c|}{ Three months } \\
\hline & $\begin{array}{l}3.40 \\
4 \cdot 38 \\
7.56 \\
4 \cdot 72 \\
3 \cdot 29\end{array}$ & $\begin{array}{l}(3 \cdot 08-3 \cdot 72) \\
(4 \cdot 03-4 \cdot 73) \\
(6 \cdot 96-8 \cdot 16) \\
(4 \cdot 16-5 \cdot 28) \\
(2 \cdot 95-3 \cdot 65)\end{array}$ & $\begin{array}{l}2 \cdot 10^{\star} \\
2 \cdot 88^{\star} \\
5 \cdot 90^{\star} \\
3 \cdot 94^{\dagger} \\
3 \cdot 23^{\dagger}\end{array}$ & $\begin{array}{l}(1 \cdot 79-2 \cdot 41) \\
(2.51-3 \cdot 25) \\
(5 \cdot 22-6.58) \\
(3 \cdot 40-4 \cdot 49) \\
(2.63-3.82)\end{array}$ & $\begin{array}{l}2.95 \\
3.98 \\
7.34 \\
4.64 \\
3.49\end{array}$ & $\begin{array}{l}(2 \cdot 70-3 \cdot 20) \\
(3 \cdot 69-4 \cdot 27) \\
(6 \cdot 42-8 \cdot 24) \\
(3 \cdot 93-5 \cdot 36) \\
(2 \cdot 82-4 \cdot 16)\end{array}$ \\
\hline
\end{tabular}

Values of $p\left({ }^{\star} p<0.001, \dagger p<0.02\right)$ were derived from paired $t$ tests of control and postoperative data.

VC-slow vital capacity; TLC—total lung capacity; FRC-functional residual capacity; RV-residual volume.

after surgery were greater in the supine than in the upright posture (mean VC sitting $66 \%$ and supine $54 \%$ of preoperative values).

With the patient in the supine position one week after operation there was a highly significant increase in respiratory frequency ( $f$ ) and a fall in tidal volume $\left(V_{T}\right)$ (table 2$)$. There were associated significant reductions in displacement of the sternum at both manubrial and xiphisternal levels and, most notably, in lateral expansion of the rib cage. The reduction of lateral chest wall motion correlated with the reduction in VC: $r_{s}<0.62, p=0.01$ (fig 3). Abdominal wall displacement was also significantly less than preoperatively but there was no relation between the reduction in abdominal displacement and the fall in VC: $r_{s}=0 \cdot 11$. With the patient in the upright position changes in rib cage motion were generally less than in the supine position; for example, lateral displacement of the rib cage in the upright position was reduced from a mean of $4.20(95 \%$ CL $2.37-6.03)$ to $2.37(95 \% \mathrm{CL}$ $1 \cdot 30-3.44) \mathrm{mm}, \mathrm{p}=0 \cdot 075$. At three months all patients showed return of all rib cage displacements towards preoperative values, with no significant difference remaining.

Discoordination of rib cage expansion and airflow occurred in 11 of the 14 patients in whom phase angles were measured (table 3 ). Nine of these patients had abnormalities of the timing of the onset of lateral chest wall motion one week after surgery $(p=0.0008$, Fisher's exact test). In four patients the abnormality amounted to frank paradox with reversal of the direction of motion during all or part of inspiration. No patient had an abnormal phase angle for abdominal wall motion one week or three months after sternotomy. Of the five subjects with delayed sternal motion, only one showed paradoxical motion of the sternum. Three months after operation persisting lateral paradox was found in one patient and two still had delayed motion of the sternum.

Table 2 Rib cage displacements during tidal breathing in the supine posture (mean ( $95 \%$ confidence limits))

\begin{tabular}{|c|c|c|c|}
\hline & Control & One week & Three months \\
\hline $\begin{array}{l}\text { Manubrium (mm) } \\
\text { Xiphoid }(\mathrm{mm}) \\
\text { Abdomen }(\mathrm{mm}) \\
\text { Lateral }(\mathrm{mm}) \\
\text { Displacement rate }\end{array}$ & $\begin{array}{cc}1.74 & (0.91-2.57) \\
2.70 & (1.57-3.84) \\
13.3 & (10.9-15.8) \\
3.87 & (1.96-5 \cdot 78) \\
16 & (13-19)\end{array}$ & $\begin{array}{cl}0.99^{\star} & (0 \cdot 26-1 \cdot 73) \\
1 \cdot 82^{\star} & (0 \cdot 57-2 \cdot 39) \\
10 \cdot 1^{\star} & (8 \cdot 2-12 \cdot 2) \\
0 \cdot 44 \dagger & (-0 \cdot 61-1 \cdot 49) \\
21^{\star \star} & (19-24)\end{array}$ & $\begin{array}{cl}1 \cdot 43 & (0 \cdot 71-2 \cdot 15) \\
2 \cdot 30 & (0 \cdot 95-3 \cdot 65) \\
12 \cdot 7 & (8 \cdot 4-17 \cdot 0) \\
2 \cdot 22 & (1 \cdot 60-2 \cdot 84) \\
17 & (13-21)\end{array}$ \\
\hline VT (1) & $0.88 \quad(0.76-1.00)$ & $0.61 \dagger \quad(0.52-0.70)$ & $0.74 \quad(0.50-0.98)$ \\
\hline
\end{tabular}

Values of $p\left({ }^{\star} p<0.05,+p<0.01,{ }^{\star \star} p<0.001\right)$ were derived from paired $t$ tests of control and postoperative data. $\triangle \mathrm{VC}$

(Ic)

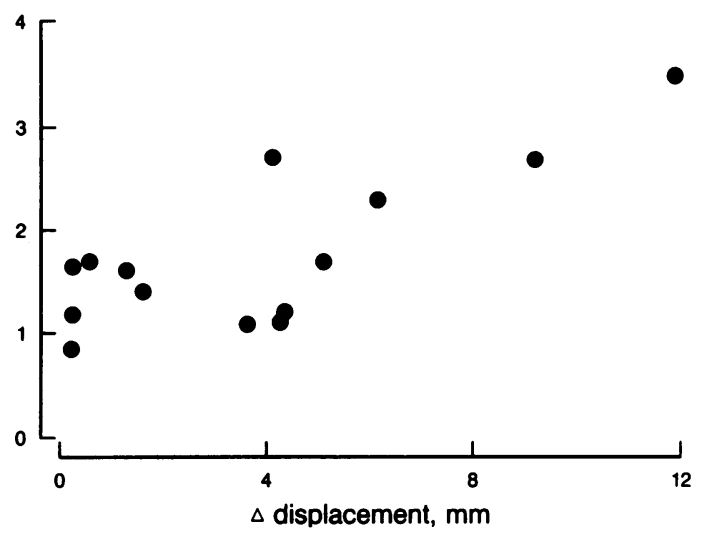

Figure 3 Relation (in 14 patients) between reductions in slow vital capacity (VC) (preoperative - postoperative values, litres) and in tidal lateral chest wall displacement $(\mathrm{mm})$, each studied in the supine posture $\left(r_{s}=0.62\right.$ $p<0.011$.

Maximal expiratory pressure fell significantly; there was a slight reduction in maximum inspiratory pressure, but this was not significant (table 4).

\section{Discussion}

Restrictive ventilatory defects after sternotomy were recognised in $1962,{ }^{12}$ but the mechanisms have not been completely elucidated. The changes are most severe in the first 48 hours after operation. ${ }^{7}$ By one week after surgery some recovery has occurred and by three months recovery is almost complete. Our values lie within the range of previous results, though in our relatively small group of patients we did not find the more substantial reduction in lung volumes associated with the use of the internal mammary artery reported by others. ${ }^{56}$ In the early stages after coronary artery bypass grafting pain atelectasis and the transient increase in lung water that follows cardiopulmonary bypass would account for a major portion of the fall in VC. ${ }^{613} \mathrm{By}$ one week, however, all the patients in the present study were ambulant and no longer required opiate analgesics; no patient complained of pain during the forced manoeuvres. Postoperative chest radiographs excluded obvious causes of major volume loss, such as lobar collapse, consolidation, or large pleural effusion. Occult pulmonary oedema cannot be excluded completely but is unlikely to contribute to an important extent to the reduction in lung volume seen one week after surgery; no patient had dyspnoea or radiographic evidence of pulmonary oedema. Fluid that accumulates in the lungs after car-

Table 3 Number of patients with abnormal phase angles

\begin{tabular}{llll}
\hline & Control & One week & Three months \\
\hline Manubrium & 0 & $5^{\star}$ & 0 \\
Xiphoid & 0 & 4 & 2 \\
Abdomen & 0 & 0 & 0 \\
Lateral & 0 & $9 \star \star$ & 1 \\
\hline
\end{tabular}

${ }^{\star} p=0.04,{ }^{\star}{ }^{\star} p=0.0008$ (Fisher's exact test). 
Table 4 Maximum respiratory pressures (mean (95\% confidence limits))

\begin{tabular}{llcllll}
\hline & \multicolumn{2}{l}{ Control } & \multicolumn{2}{l}{ One week } & \multicolumn{2}{c}{ Three months } \\
\hline PEmax $\left(\mathrm{cmH}_{2} \mathrm{O}\right)$ & 150 & $(109-191)$ & $80^{\star}$ & $(50-109)$ & 113 & $(70-156)$ \\
$\operatorname{PImax}\left(\mathrm{cmH}_{2} \mathrm{O}\right)$ & 100 & $(49-150)$ & 83 & $(44-123)$ & 80 & $(38-122)$ \\
\hline
\end{tabular}

The value of $\mathrm{p}\left({ }^{\star} \mathrm{p}<0.01\right)$ was derived from a paired $t$ test of control and postoperative data.

PEmax-maximum expiratory pressure; PImax - maximum inspiratory pressure.

diopulmonary bypass has usually cleared by 48 hours after operation, ${ }^{13} 14$ and there is little difference in lung compliance before and 8-13 days after coronary artery grafting. ${ }^{15}$

Estenne et al ${ }^{4}$ investigated diaphragmatic function postoperatively and showed normal phrenic nerve condution times in 11 of 12 patients after saphenous vein grafting, suggesting that phrenic injury is unlikely to contribute to volume reduction in most patients. In the present study indirect indices of diaphragmatic function (PImax, abdominal motion phase angle, and chest radiograph) support the conclusion that weakness of the diaphragm was not a factor in the postoperative change in pulmonary function. The small but significant decrease in supine abdominal wall displacement during tidal breathing at one week might be explained by the extension of the sternotomy into the upper abdomen, producing reflex inhibition of motion. ${ }^{16}$ Similar factors may account for the impressive reduction in PEmax, which presumably reflects impaired function of the abdominal wall muscles.

Pleurotomy seems unlikely to be relevant to the abnormalities found: mobilisation of the left internal mammary artery was performed without pleurotomy if possible, and the pleural space was entered in only two patients; furthermore, the patients who had only saphenous vein grafting showed changes similar to those of the ones who also had internal mammary artery grafting. No patient had an intercostal drain, which may increase respiratory abnormalities. $^{26}$

The possibility that alterations of rib cage mechanics ${ }^{14}$ play a part in the reduction of lung volumes is suggested by the generalised decrease in rib cage motion and the relation between the decrease in vital capacity and the reduction of lateral rib cage motion. Two patterns of abnormality of chest wall movement were identified. Five patients had a simple reduction of displacement in one or more planes without any significant changes in the timing of the onset of chest wall motion; the remainder had abnormalities of timing of chest wall motion and consequently reduced displacements. The presence of frank paradox of the lateral rib cage dimension in four patients represents an extreme form of this type of discoordination. A possible mechanism may be trauma to the costovertebral joints, producing reflex inhibition of intercostal muscle contraction such that the rib cage is unable to resist the inward force of diaphragmatic contraction. ${ }^{17}$ There may also be a change in the bony configuration of the chest wall after sternotomy with a increase in thoracic spinal curvature and lowering of the ribs. ${ }^{18}$

We conclude that the restrictive ventilatory defect that follows median sternotomy is likely to be due in part to alterations in rib cage mechanics.

We thank Mr AH Brown and Mr CGA McGregor for permission to study their patients.

1 Braun SR, Birnbaum ML, Chopra PS. Pre- and postoperative pulmonary function abnormalities in coronary artery revascularisation surgery. Chest 1978;73:316-20.

2 Burgess GE, Cooper JR, Marino RJ, et al. Pulmonary effec of pleurotomy during and after coronary artery surgery with internal mammary artery versus saphenous vein grafts. J Thorac Cardiovasc Surg 1978;76:230-4.

3 Stock MC, Downs JB, Weaver D, et al. Effect of pleurotomy on pulmonary function after median sternotomy. Ann Thorac Surg 1986;42:441-4.

4 Estenne M, Yernault J-C, De Smet J-M, DE Troyer A. Phrenic and diaphragm function after bypass grafting. Thorax 1985;40:293-9.

5 Berrizbeita LD, Tessler S, Lenora RAK, et al. Effect of sternotomy and coronary bypass surgery on postoperative pulmonary mechanics [abstract]. Am Rev Respir Dis 1988;137:248.

6 Jenkins SC, Soutar SA, Forsyth A, Keates JRW, Moxham J. Lung function after coronary artery surgery using the internal mammary artery and the saphenous veins. Thorax 1989;44:209-11.

7 Peters RM. Pulmonary function and its evaluation. In: Glenn WWL, Baue AE, Geha AS, Hammond GL, Laks $\mathrm{H}$, eds. Thoracic and cardiovascular surgery. Norwalk, Connecticut: Appleton-Century-Crofts, 1983.

8 Dubois AB, Bothelo SY, Bedell GN, et al. A rapid plethysmographic method for measuring thoracic gas volume: a comparison with a nitrogen washout method for measuring functional cap

1956;35:322-6.
Griffiths CJ, Gilmartin JJ, Gibson GJ, Murray A Measurement of chest wall movement: design, performance, and clinical use of a four-channel magnetometer instrument. Clin Phys Physiol Meas 1983;4:363-71.

10 Konno K, Mead J. Measurement of the separate volume changes of the rib cage and abdomen during breathing. Appl Physiol 1971;22:407-22.

11 Hillman DR, Prentice L, Finucane KE. The pattern of breathing in acute severe asthma. Am Rev Respir Dis 1986;133:587-92.

12 Howatt WF, Talner NS, Sloan $\mathrm{H}$, et al. Pulmonary function changes following repair of heart lesions with the aid of extracorporeal

13 Cohn LH, Angell WW, Shumway NE. Body fluid shifts after cardiopulmonary bypass. I. Effects of congestive heart failure and haemodilution. J Thorac Cardiovasc Surg 1971;62:423-30.

14 Pacifico AD, Digerness S, Kirklin JW. Acute alterations of body composition after open intracardiac operations. Circulation 1970;41:331-41.

15 Estenne M, De Smet JM, De Troyer A, Yernault JC. Effects of coronary artery bypass surgery on respiratory mechanof coronary artery bypass surgery on respiratory

16 Ali J, Weisel RD, Layug AB, et al Consequences of postoperative alterations in respiratory mechanics. Am J Surg operative alterations

17 Gilmartin JJ, Gibson GJ. Abnormalities of chest wall motion in patients with chronic airflow obstruction. Thorax 1984;39:264-71

18 Kenyon CM, Pedley T, Higenbottam T. Changes in chest wall configuration following medial sternotomy [abstract] Clin Sci 1987;73(suppl 17):22. 